\title{
Systematic review and meta-analysis: safety of ultrasound-guided peripheral venipuncture and catheterization
}

\author{
Xuan Xiong', Yilin Xiong' ${ }^{2}$, Guangfu Liu ${ }^{3}$ \\ ${ }^{1}$ Department of Critical Care Medicine, The Affiliated Hospital of Southwest Medical University, Luzhou, China; ${ }^{2}$ Department of Interventional \\ Medicine, Health Center, The Affiliated Hospital of Southwest Medical University, Luzhou, China; ${ }^{3}$ Nuclear Medicine, The Affiliated Hospital of \\ Southwest Medical University, Luzhou, China \\ Contributions: (I) Conception and design: X Xiong, Y Xiong; (II) Administrative support: G Liu; (III) Provision of study materials or patients: X \\ Xiong, G Liu; (IV) Collection and assembly of data: All authors; (V) Data analysis and interpretation: All authors; (VI) Manuscript writing: All \\ authors; (VII) Final approval of manuscript: All authors. \\ Correspondence to: Xuan Xiong. Department of Critical Care Medicine, The Affiliated Hospital of Southwest Medical University, 25 Taiping Street, \\ Luzhou, China. Email: xx1020300@163.com.
}

Background Vascular punctures are widely used in clinical applications; however, clinical trials have identified complications and poor prognosis for patients undergoing common peripheral vein puncture as compared to ultrasound-guided peripheral venipuncture and catheterization. Ultrasound-guided peripheral venipuncture and catheterization is accurate, simple, has fewer associated complications, and will gradually take the place of common peripheral vein puncture.

Methods: To study the safety of ultrasound-guided peripheral venous catheterization, a meta-analysis was conducted of relevant articles dating from establishment date of the database (such as PubMed, MEDLINE and EMBASE) to March 2021, with the search keywords being peripheral venipuncture, ultrasound guidance, vascular injury rate, and hematoma formation rate. A total of 8 trials were used to determine accuracy indicators, which included puncture failure rate, arterial injury rate, hematoma formation rate, pneumothorax incidence rate, and hemothorax incidence rate.

Results: There were statistically significant differences between the two methods for peripheral venipuncture and catheterization in terms of puncture failure rate [odds ratio $(\mathrm{OR})=0.08$; $95 \%$ CI: $0.04-$ 0.16; $\mathrm{P}<0.00001$ ], incidence of vascular injury ( $\mathrm{OR}=0.15 ; 95 \% \mathrm{CI}: 0.07-0.32 ; \mathrm{P}<0.00001$ ), probability of hematoma formation during the puncture process ( $\mathrm{OR}=0.24 ; 95 \% \mathrm{CI}: 0.08-0.69 ; \mathrm{P}=0.008)$, and probability of pneumothorax during puncture (OR $=0.10 ; 95 \% \mathrm{CI}: 0.02-0.55 ; \mathrm{P}=0.008)$.

Discussion: Eight articles were included for meta-analysis. Ultrasound-guided peripheral venipuncture and catheterization is a commonly used puncture method for patients needing rapid fluid infusion with pressure or a pressure pump, repeated transfusion of blood product, or multiple daily venous blood drawing test. The results were very clear, and the puncture failure rate and other complications of ultrasound-guided peripheral venipuncture catheterization were low.

Keywords: Ultrasonic guidance; peripheral venipuncture catheterization; security; meta-analysis

Submitted Sep 13, 2021. Accepted for publication Nov 16, 2021.

doi: 10.21037/apm-21-3163

View this article at: https://dx.doi.org/10.21037/apm-21-3163 


\section{Introduction}

Vascular catheterization, including arterial catheterization, peripheral venous catheterization, and central venous catheterization, exerting critical role in the clinical treatment of patients with a variety of acute and critical diseases. Peripheral venipuncture catheterization involves puncturing a vein of the peripheral arm with a catheter and then directing the catheter to a large vein close to the heart to avoid direct contact between chemotherapy drugs and the vein in the arm. As the blood flows fast in the superior vena cava, the chemotherapy drugs may be quickly eliminated and the interaction of the drug with the blood vessel can be minimized (1-3). Peripheral venipuncture and catheterization is primarily suitable for long-term intravenous infusion where the condition of superficial peripheral veins is poor and it is difficult to achieve a successful puncture. Applications include repeated infusions of stimulant drugs, such as chemotherapy drugs; long-term introduction of drugs with high permeability or viscosity, such as high sugar/fat milk, amino acid; or rapid infusion using a pressure or pressurized pump, such as an infusion pump (4-6). However, peripheral venipuncture and catheterization also has its limitations. It is not suitable for patients whose physical condition can't tolerate intravenous cannulation, such as patients with coagulation mechanism disorder or immunosuppression (7-9). Patients with a history of phlebitis, venous thrombosis, trauma, or vascular surgery at the predetermined site of venipuncture are also unsuitable, as well as those with local tissue factors affecting the stability or patency of the catheter (10).

During a peripheral venipuncture and catheterization procedure, patients are usually placed in the supine position, and the length of the patient from the puncture site to the superior vena cava is measured with a tape measure, generally $45-48 \mathrm{~cm}$. After the puncture site is selected, the hemostatic band is tied, routine disinfection is performed, and the peripherally inserted central catheter (PICC) venipuncture is performed according to the instructions, with the length of catheter reserved based on actual conditions of patients. After puncture, an X-ray is taken (11). Studies have shown that peripheral venipuncture can reduce the patients' pain due to repeated venipuncture, is simple and easy, and can be performed directly in the ward with no limitations on time or place $(12,13)$. Since the catheter can access the superior vena cava with fast blood flow, peripheral venipuncture catheterization can quickly reduce local tissue pain, necrosis, and phlebitis due to fluid osmotic pressure or chemotherapeutic drugs (14). Patients undergoing early catheterization will almost never sustain venous injury in the course of chemotherapy, ensuring that good venous access can be maintained and that chemotherapy treatments can be completed successfully (15). Peripheral venipuncture catheterization has become a convenient, safe, fast, and effective means of providing vein access for longterm intravenous nutrition support and medication for patients with critical illness, and for patients undergoing the chemotherapy (16).

The factors that affect the success rate of puncture include the condition of the vein itself, the puncture site, the patient's condition, the puncture technique, and the way of delivery. Traditional blind puncture cannot correctly judge the thickness of blood vessels, venous valves and branches, which leads to a low success rate of catheter placement. There are more complications. Continuous improvements in medical technology have led to the application of ultrasound to vascular puncture and catheterization (17). Ultrasound-guided puncture was first proposed in 1984, and subsequent studies have demonstrated that it improves conventional puncture techniques in anesthesia and the intensive care unit (ICU) (18). In recent years, with new developments in medical instrumentation, reports on real-time 2-dimensional ultrasound (RTUS) guidance techniques have been increasing, and a growing number of studies have confirmed the advantages of deep venipuncture catheterization using RTUS (19). Ultrasound-guided PICC catheter placement can significantly increase the success rate of catheter placement and improve the incidence of mechanical phlebitis, bleeding at the puncture site, and finger swelling.

The current ultrasound-guided peripheral venipuncture research mainly focuses on adult tumor chemotherapy patients, and there are relatively few studies on children. This study was to explore the safety of ultrasound-guided peripheral venous catheterization. Eight articles were obtained finally with various screening and meta-analyses methods. It could provide a theoretical scientific basis for improving the success rate and reducing the incidence of dangerous events in ultrasound-guided peripheral venipuncture and catheterization.

We present the following article in accordance with the PRISMA reporting checklist (available at https://dx.doi. org/10.21037/apm-21-3163). 


\section{Methods}

\section{Search strategy}

PubMed, MEDLINE, EMBASE, and Cochrane Central Register of Controlled Trials, were searched for a combination of related keywords and medical subject title terms for postoperative pulmonary complications. Search restrictions limited results to studies published from January 12001 , to March 20, 2021. The start date was chosen to overlap with the last system review on prevention strategies. Search keywords and terms included the following: peripheral venipuncture, ultrasound guidance, arterial injury rate, hematoma formation rate, pneumothorax incidence rate, and hemothorax incidence rate. The full text of articles was obtained to allow manual screening in accordance with predetermined criteria for inclusion and exclusion.

\section{How to include or exclude the articles}

Articles met the following items could be included: (I) the participants were patients undergoing peripheral venipuncture and catheterization; (II) the patients had reached the age of 18 years; (III) the patients were examined in a randomized controlled trial or a study based on a clinical trial; (IV) the article contained target keywords; (V) only published articles were considered for inclusion; and (VI) relevant intervention measures included the experimental group (Exp group) being catheterized by peripheral venipuncture guided by ultrasound and the control group (Con group) being catheterized by peripheral venipuncture guided by an anatomical marker.

Articles which satisfied the below items had to be excluded: (I) articles that in essence reported findings published in earlier work; (II) articles without the required indicators, (III) nonclinical trials, (IV) studies involving other methods of venipuncture, (V) Chinese-language literature, (VI) other meta-analyses that used references rather than including literature, and (VII) fuzzy results and/ or incomplete data.

\section{Screening process}

Two researchers were invited to screen the articles independently and discuss to confirm the results. If different opinions arose, other experts were consulted to refine the data selection.

\section{Data extraction}

Data were extracted from the selected articles into Microsoft Excel tables, including basic literature information (title, author, year of publication, author information, and literature sources), the general data of the participants (gender, age, study sample size, and baseline comparability), research design and method, intervention measures, outcome indicators, bias evaluation, and others. The data were extracted independently by the two researchers, and afterwards a cross-check was performed. Any differences in the tables were resolved either by discussion between the two researchers or in consultation with a third researcher.

\section{Quality assessment}

The articles were evaluated using the bias-risk assessment criteria defined by Cochrane Handbook for Systematic Reviews of Intervention 5.0.2. The evaluation items were given as follows: (I) application of a random sequence (which referred to whether the research objects were randomly grouped); (II) implementation of allocation hiding (i.e., whether the participants did not know the random group); (III) whether the participants knew the research and the grouping information; (IV) blinded outcome assessor (which referred to the researcher or outcome assessor knew nothing about the participant); (V) complete data, (VI) whether the survey results could be trusted, and (VII) other biases. If any inconsistent result was obtained by the two researchers, it can be discussed to get the agreed result, or otherwise, it can be arbitrated by a third party (Table 1).

\section{Data analysis}

The forest map combined Cos also clarified the articles information. No overlap shown by CI indicated statistical heterogeneity was obvious among the articles, so it had to be analyzed further to obtain the acceptable inhomogeneity using fixed effect model (FEM). It can be divided into subgroups with different designs. The influence size of each subgroup can be ignored when the heterogeneity can't be ignored when different properties can't be dealt with in order to deal with the heterogeneity. The combined statistical model of the statistical model was selected. Sensitivity analysis on results was completed to analyze if any article alone could affect the overall results. In general, this study can be expected to have an impact on the 
Table 1 Quality assessment of the included literature

\begin{tabular}{|c|c|c|c|c|c|c|c|}
\hline The first author & Random method & $\begin{array}{l}\text { Distribution } \\
\text { method }\end{array}$ & $\begin{array}{l}\text { Blinding of } \\
\text { patient and } \\
\text { investigator }\end{array}$ & $\begin{array}{l}\text { Blinding of } \\
\text { outcome } \\
\text { evaluators }\end{array}$ & $\begin{array}{l}\text { Integrity of } \\
\text { the resulting } \\
\text { data }\end{array}$ & $\begin{array}{l}\text { Selectively } \\
\text { reported } \\
\text { research results }\end{array}$ & $\begin{array}{l}\text { Other } \\
\text { sources } \\
\text { of bias }\end{array}$ \\
\hline Agarwal 2009; (21) & UC & UC & No & No & Complete & UC & UC \\
\hline Airapetian 2013; (22) & Table of random numbers & UC & No & No & Complete & UC & UC \\
\hline Grebenik 2004; (24) & UC & UC & No & No & UC & UC & UC \\
\hline Karakitsos 2006; (25) & Table of random numbers & Sealed envelope & No & No & Complete & UC & UC \\
\hline Leung 2006; (26) & Computer randomization & Sealed envelope & No & No & Complete & UC & UC \\
\hline Milling 2005; (27) & Table of random numbers & Sealed envelope & No & No & Complete & UC & UC \\
\hline
\end{tabular}

"UC" in the table above referred to "Unclear".

comprehensive study in the following two situations. First, the presumed size of the combined effect is $95 \%$ greater, and results will be significantly different when a study is deleted. If there is little difference in the results of one study affecting the whole, it indicates the sensitivity is unstable. However, sensitivity analysis showed that the findings were stable and that the conclusion was reliable.

\section{Statistical analysis}

RevMan 5.3 software provided by The Cochrane Collaboration was used for the meta-analysis. Odds ratio (OR) was undertaken as the effect size, and the outcome was represented with $95 \%$ CIs. Heterogeneity of the included studies was first tested with $\alpha=0.1$ to be the test level. If heterogeneity was not found $\left(\mathrm{P}>0.10, \mathrm{I}^{2}<50 \%\right)$, FEM was applied for the meta-analysis among all articles. $\mathrm{P}$ value $<0.05$ was adopted to show the statistically significant difference. If there were more than 10 articles to perform the single risk factor, funnel plots were adopted to analyze the publication bias, which was drawn by RevMan 5.3. If the result showed a $\mathrm{P}$ value $>0.05$, there was no publication bias; otherwise, there was publication bias.

\section{Results}

\section{Researched articles}

A total of 3,340 articles were retrieved from the database, and 1,298 articles were retrieved from registers. After reading the article, 2,042 articles that did not meet the requirements were initially eliminated. After reading the article title and abstract, 2,014 articles that did not meet the inclusion and exclusion criteria were eliminated. After further reading the abstract, 549 articles were eliminated. After reading the full text of the article carefully and eliminating 25 documents, finally, a total of 8 documents meeting the requirements were included for meta-analysis (20-27) (Figure 1, Table 2).

\section{Bias risk assessment}

The Cochrane Handbook for Systematic Reviews of Intervention 5.0.2 was used to evaluate the risk of bias in 8 articles selected for inclusion. RevMan 5.3 was adopted to draw the results in chart (Figures 2,3).

\section{Failure rate of peripheral venipuncture and catheterization under ultrasound guidance}

Of the 8 studies included in this meta-analysis, 7 reported the incidence of puncture failure during peripheral vascular catheterization of patients. For this analysis, there were 890 patients in Exp group and 907 cases in Con group. Significant heterogeneity was found $\left(\mathrm{I}^{2}=10 \% ; \mathrm{P}=0.35\right)$, so meta-analysis was performed using FEM. The results yielded an OR of 0.08 (95\% CI: 0.04-0.16; $Z=6.97$; $\mathrm{P}<0.00001)$. Therefore, difference in the incidence of puncture failure was obvious between the two groups under different puncture methods ( $\mathrm{P}<0.05$; Figure 4$)$. 

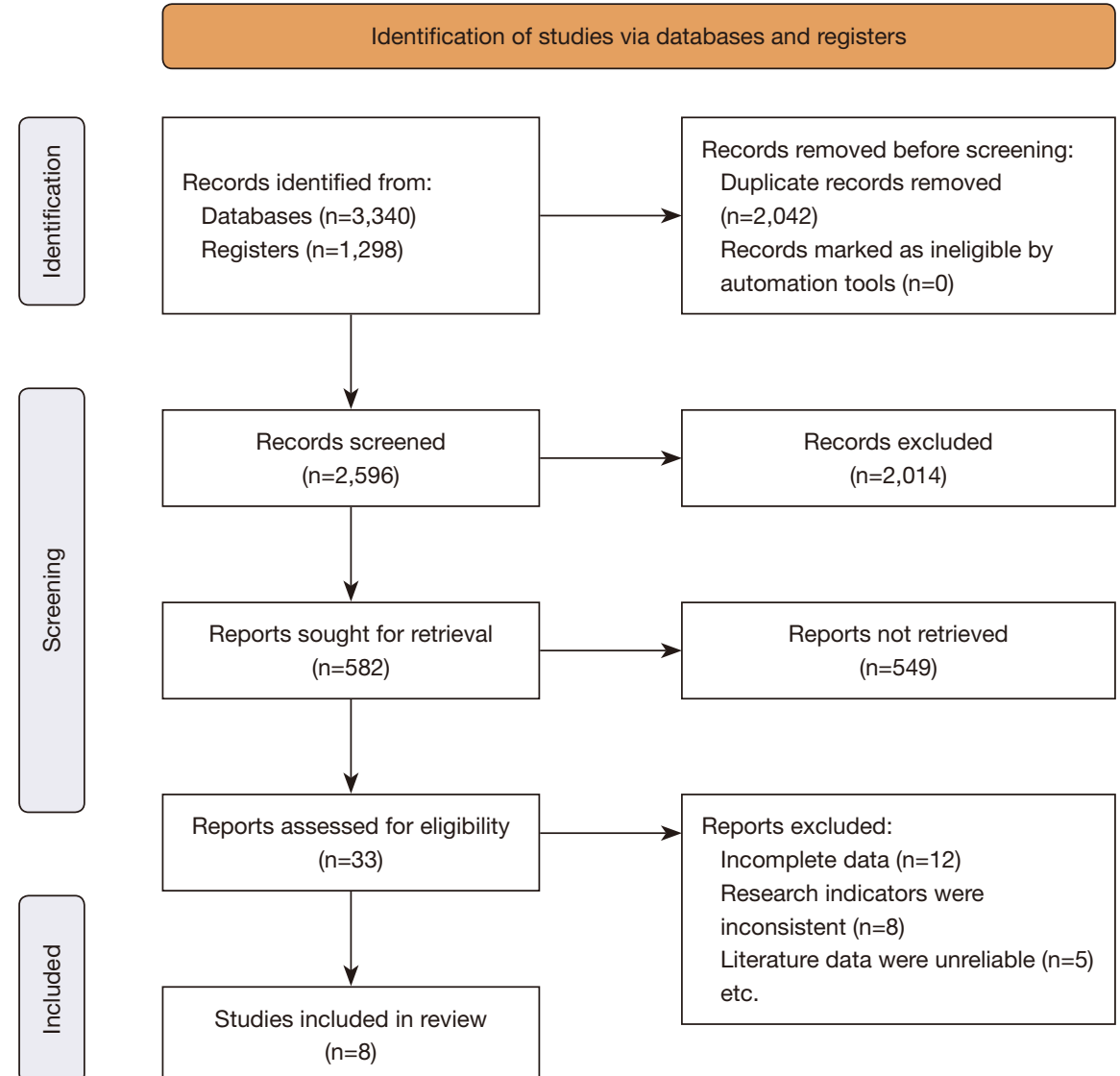

Figure 1 Literature retrieval process.

Table 2 Basic data of the articles

\begin{tabular}{|c|c|c|c|c|c|c|c|}
\hline $\begin{array}{l}\text { The first } \\
\text { author }\end{array}$ & $\begin{array}{l}\text { Country/ } \\
\text { region }\end{array}$ & $\begin{array}{l}\text { Number of cases } \\
\text { (Exp group/Con } \\
\text { group) }\end{array}$ & $\begin{array}{l}\text { Average } \\
\text { age (years) }\end{array}$ & $\begin{array}{l}\text { Diagnostic } \\
\text { ultrasonic } \\
\text { instrument }\end{array}$ & $\begin{array}{l}\text { Intervention } \\
\text { in the Exp group }\end{array}$ & $\begin{array}{l}\text { Intervention } \\
\text { in Con group }\end{array}$ & $\begin{array}{l}\text { Outcome } \\
\text { indicators }\end{array}$ \\
\hline $\begin{array}{l}\text { Airapetian } \\
2013 ;(22)\end{array}$ & French & $36 / 38$ & 65 & Dymax & $\begin{array}{l}\text { Peripheral venipuncture } \\
\text { and catheterization } \\
\text { were conducted under } \\
\text { ultrasonic guidance }\end{array}$ & $\begin{array}{l}\text { Peripheral venipuncture } \\
\text { and catheterization were } \\
\text { performed under the location } \\
\text { of anatomical markers }\end{array}$ & (l) \\
\hline
\end{tabular}

Table 2 (continued) 
Table 2 (continued)

\begin{tabular}{|c|c|c|c|c|c|c|c|}
\hline $\begin{array}{l}\text { The first } \\
\text { author }\end{array}$ & $\begin{array}{l}\text { Country/ } \\
\text { region }\end{array}$ & $\begin{array}{l}\text { Number of cases } \\
\text { (Exp group/Con } \\
\text { group) }\end{array}$ & $\begin{array}{l}\text { Average } \\
\text { age (years) }\end{array}$ & $\begin{array}{l}\text { Diagnostic } \\
\text { ultrasonic } \\
\text { instrument }\end{array}$ & $\begin{array}{l}\text { Intervention } \\
\text { in the Exp group }\end{array}$ & $\begin{array}{l}\text { Intervention } \\
\text { in Con group }\end{array}$ & $\begin{array}{l}\text { Outcome } \\
\text { indicators }\end{array}$ \\
\hline $\begin{array}{l}\text { Karakitsos } \\
\text { 2006; (25) }\end{array}$ & Greek & $450 / 450$ & 58.7 & ATL 3500 & $\begin{array}{l}\text { Peripheral venipuncture } \\
\text { and catheterization } \\
\text { were conducted under } \\
\text { ultrasonic guidance }\end{array}$ & $\begin{array}{l}\text { Peripheral venipuncture } \\
\text { and catheterization were } \\
\text { performed under the location } \\
\text { of anatomical markers }\end{array}$ & $\begin{array}{l}\text { (I); (II); } \\
\text { (IV); (V) }\end{array}$ \\
\hline $\begin{array}{l}\text { Milling } \\
\text { 2005; (27) }\end{array}$ & $\begin{array}{l}\text { The United } \\
\text { States }\end{array}$ & $60 / 69$ & 71.9 & SonoSite & $\begin{array}{l}\text { Peripheral venipuncture } \\
\text { and catheterization } \\
\text { were conducted under } \\
\text { ultrasonic guidance }\end{array}$ & $\begin{array}{l}\text { Peripheral venipuncture } \\
\text { and catheterization were } \\
\text { performed under the location } \\
\text { of anatomical markers }\end{array}$ & (I); (V) \\
\hline
\end{tabular}

(I) Puncture failure rate; (II) arterial injury rate; (III) hematoma formation rate; (IV) incidence of pneumothorax; (V) incidence of hemothorax.

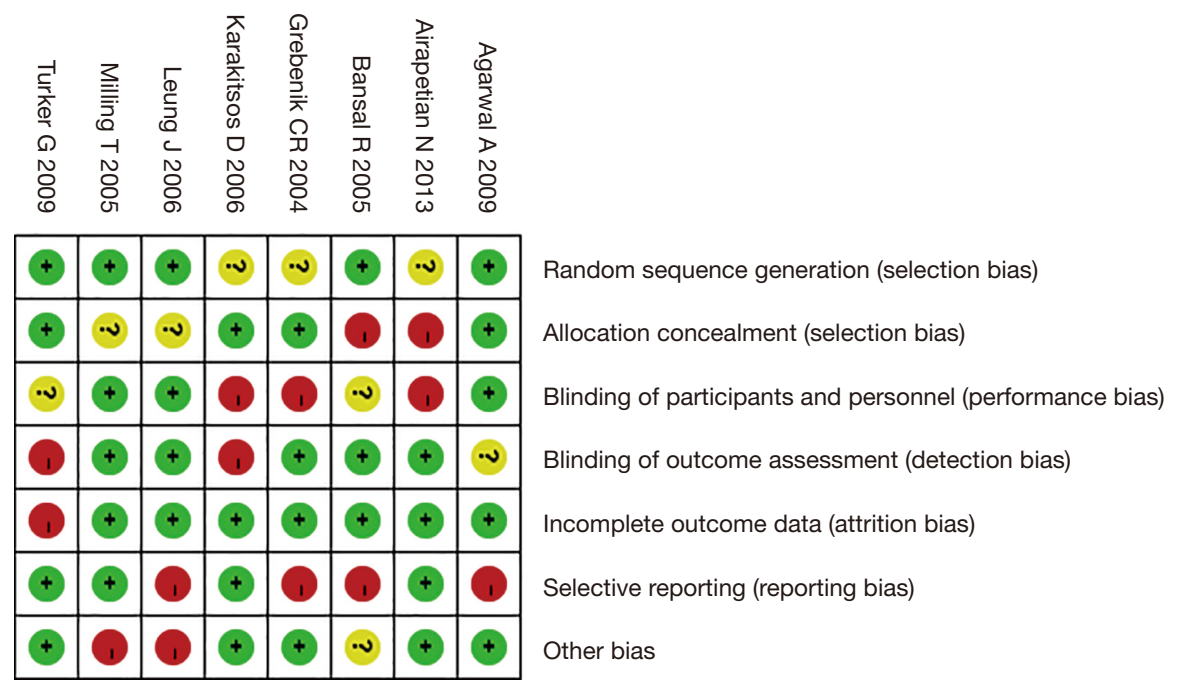

Figure 2 Bias risk assessment diagram of articles. 


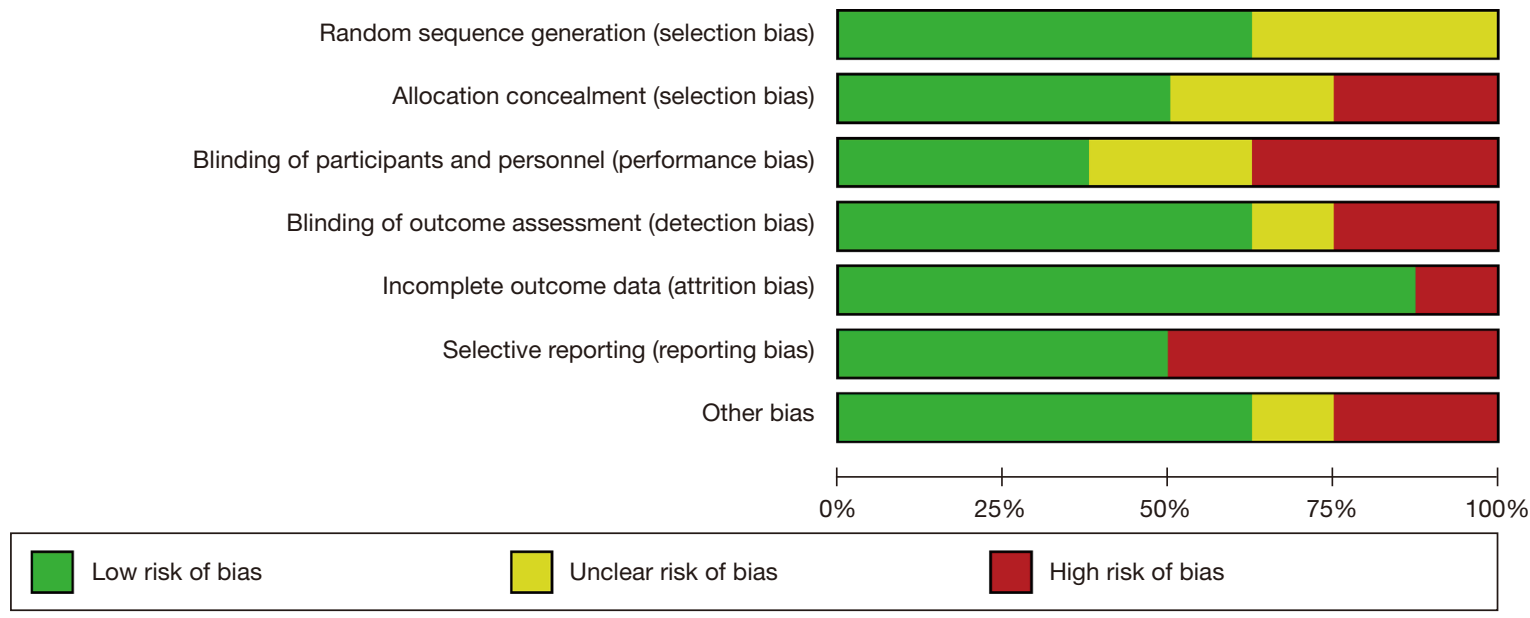

Figure 3 Bias evaluation bar graph of articles.

\begin{tabular}{|c|c|c|c|c|c|c|c|c|c|}
\hline Study or Subgroup & \multicolumn{2}{|c|}{ Experimental } & \multicolumn{2}{|c|}{ Control } & \multicolumn{2}{|c|}{$\begin{array}{cc} & \text { Odds Ratio } \\
\text { Weight } & \text { M-H, Fixed, } 95 \% \mathrm{Cl} \\
\end{array}$} & \multicolumn{3}{|c|}{$\begin{array}{c}\text { Odds Ratio } \\
\text { M-H, Fixed, } 95 \% \mathrm{Cl}\end{array}$} \\
\hline Airapetian N 2013 & 0 & 36 & 10 & 38 & $11.2 \%$ & $0.04[0.00,0.66]$ & & & \\
\hline Bansal R 2005 & 0 & 30 & 2 & 30 & $2.7 \%$ & $0.19[0.01,4.06]$ & & & \\
\hline Grebenik CR 2004 & 1 & 59 & 12 & 65 & $12.4 \%$ & $0.08[0.01,0.61]$ & & & \\
\hline Karakitsos D 2006 & 0 & 450 & 25 & 450 & $28.2 \%$ & $0.02[0.00,0.31]$ & & & \\
\hline Leung J 2006 & 4 & 65 & 14 & 65 & $14.6 \%$ & $0.24[0.07,0.78]$ & & & \\
\hline Milling T 2005 & 1 & 60 & 25 & 69 & $25.3 \%$ & $0.03[0.00,0.23]$ & & & \\
\hline Turker G 2009 & 1 & 190 & 5 & 190 & $5.5 \%$ & $0.20[0.02,1.69]$ & & & \\
\hline Total $(95 \% \mathrm{Cl})$ & & 890 & & 907 & $100.0 \%$ & $0.08[0.04,0.16]$ & & & \\
\hline Total events & 7 & & 93 & & & & & & \\
\hline $\begin{array}{l}\text { Heterogeneity: } \mathrm{Chi}^{2}= \\
\text { Test for overall effect }\end{array}$ & $\begin{array}{l}6.69, \mathrm{df}= \\
Z=6.97(\end{array}$ & $\begin{array}{l}(P=0 \\
<0.00\end{array}$ & $\begin{array}{l}35) ;\left.\right|^{2}=1 \\
001)\end{array}$ & $10 \%$ & & & $\begin{array}{cc}0.001 & 0.1 \\
\text { Favours [experimental] }\end{array}$ & 10 & 1000 \\
\hline
\end{tabular}

Figure 4 Forest plot comparing the puncture failure rates of peripheral venipuncture catheterization under ultrasound guidance to those of traditional methods.

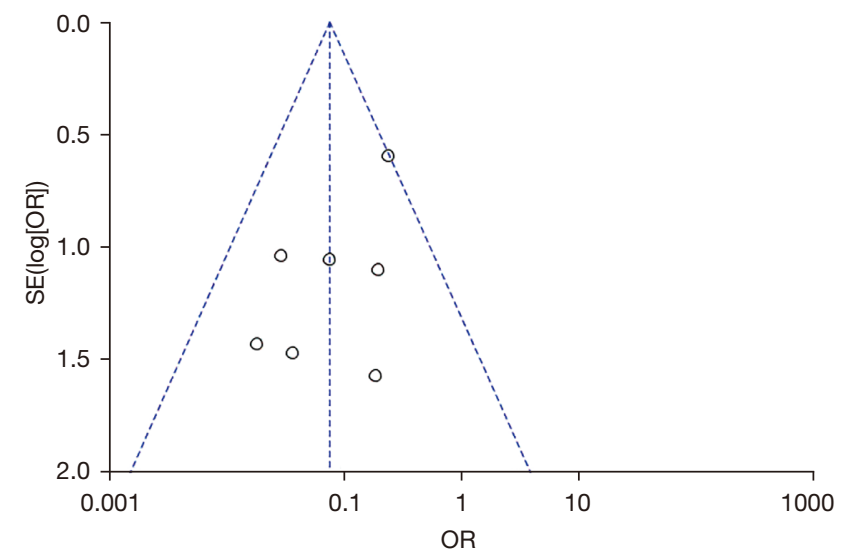

Figure 5 Funnel plot comparing puncture the failure rates of peripheral venipuncture catheterization under ultrasound guidance to those of traditional methods.
The funnel plot was basically symmetrical, and most of the data corresponded to points within the $95 \%$ CI. It suggests that there was no big publication bias in the correlation of the puncture failure rate in patients with different puncture methods (Figure 5).

\section{Meta-analysis of the vascular injury rate of peripheral venipuncture and catbeterization guided by ultrasound}

Of the 8 studies included in this meta-analysis, 5 reported the incidence of arterial injury during peripheral vascular puncture and catheterization. For this analysis, there were 794 and 800 patients in the Exp group and Con group, respectively. Obvious heterogeneity was found $\left(\mathrm{I}^{2}=0 \%\right.$; $\mathrm{P}=0.98)$. The results using FEM yielded an OR of $0.15(95 \%$ 


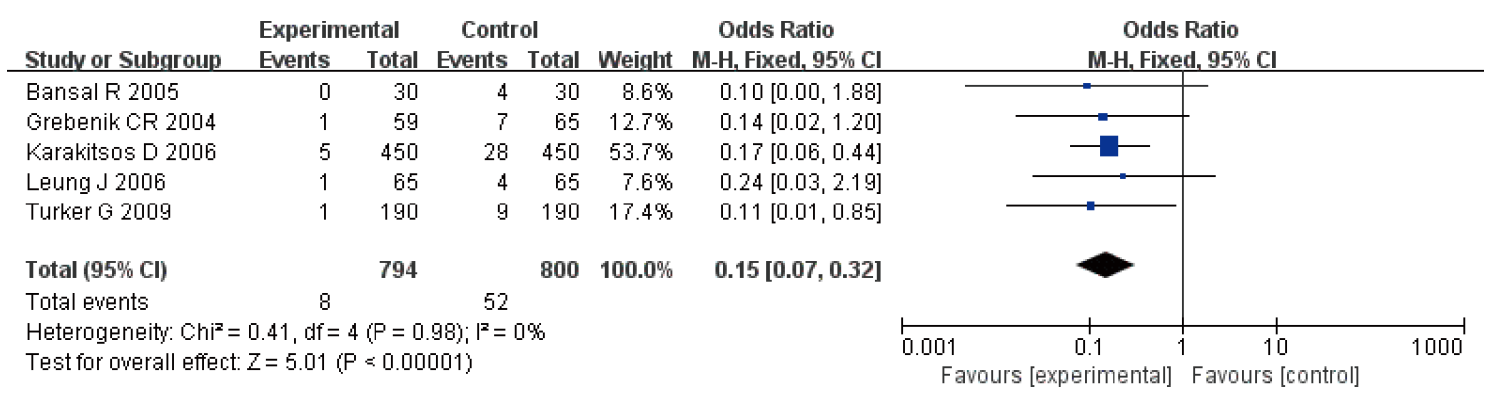

Figure 6 Forest plot comparing the incidence of vascular injury during ultrasound-guided peripheral venipuncture catheterization to that of traditional methods.

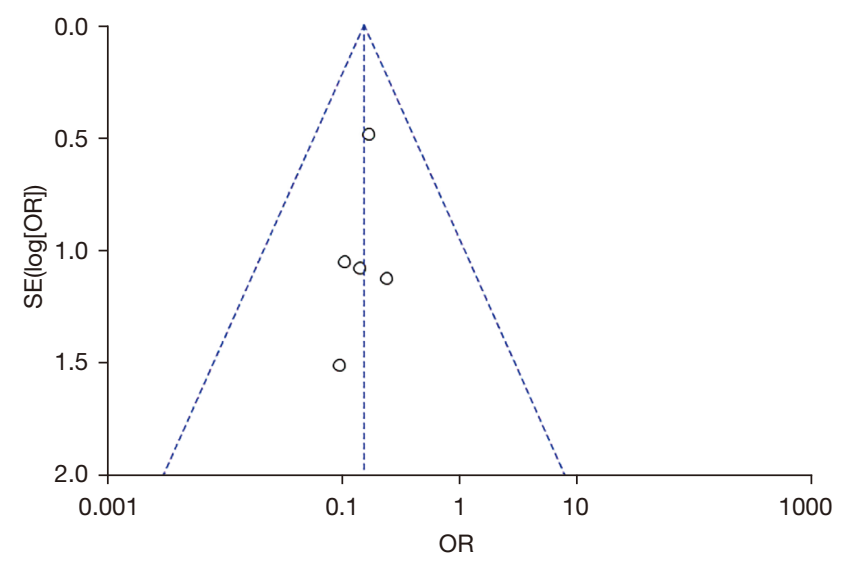

Figure 7 Funnel plot comparing the incidence of vascular injury during ultrasound-guided peripheral venipuncture catheterization to that of traditional methods.

CI: $0.07-0.32 ; \mathrm{Z}=5.01 ; \mathrm{P}<0.00001)$. Therefore, difference in the incidence of vascular alignment was great between the two groups under different puncture methods $(\mathrm{P}<0.05$; Figure 6).

The funnel plot was basically symmetrical, and most of the data corresponded to points within the $95 \%$ CI. The inverted funnel chart is basically symmetrical, and all the documents fall into the funnel. Therefore, there was no big publication bias (Figure 7).

\section{Meta-analysis of the hematoma formation rate of peripheral venipuncture catheterization guided by ultrasound}

Of the 8 studies included in this meta-analysis, 3 reported the hematoma formation rate during peripheral vascular puncture and catheterization of patients. For this analysis, 285 patients were enrolled in both the experimental and Con groups. Significant heterogeneity was shown among the articles $\left(\mathrm{I}^{2}=0 \% ; \mathrm{P}=0.90\right)$, so $\mathrm{FEM}$ was selected for meta-analysis, which showed an OR of 0.24 (95\% CI: 0.08-0.69; $\mathrm{Z}=2.64 ; \mathrm{P}=0.008)$. Therefore, the difference in the hematoma formation rate was visible between the two groups using different puncture methods $(\mathrm{P}<0.05$; Figure 8$)$.

The funnel plot was essentially symmetrical, and most of the data corresponded to points within the 95\% CI. And the inverted funnel chart is basically symmetrical, and all the documents fall into the funnel. Therefore, there was no obvious publication bias in the included documents (Figure 9).

\section{Meta-analysis of the incidence of pneumothorax with peripheral venipuncture and catheterization guided by ultrasound}

Of the 8 studies included in this meta-analysis, 3 reported the incidence of pneumothorax during peripheral vascular puncture and catheterization. For this analysis, there were 555 patients in both the experimental and Con groups. Heterogeneity was obvious among the articles $\left(\mathrm{I}^{2}=0 \%\right.$; $\mathrm{P}=0.50$ ), so meta-analysis was realized using FEM. The results yielded an OR of 0.10 (95\% CI: $0.02-0.55$; $Z=2.66$; $\mathrm{P}=0.008)$. Therefore, great difference was found in the incidence of pneumothorax between the two groups under different puncture methods $(\mathrm{P}<0.05$; Figure 10$)$.

The funnel plot was basically symmetrical, and most of the data corresponded to points within the $95 \%$ CI. The drawn inverted funnel graph is basically symmetrical, and all 3 documents fall into the graph. Therefore, there was no obvious publication bias in the literature (Figure 11). 


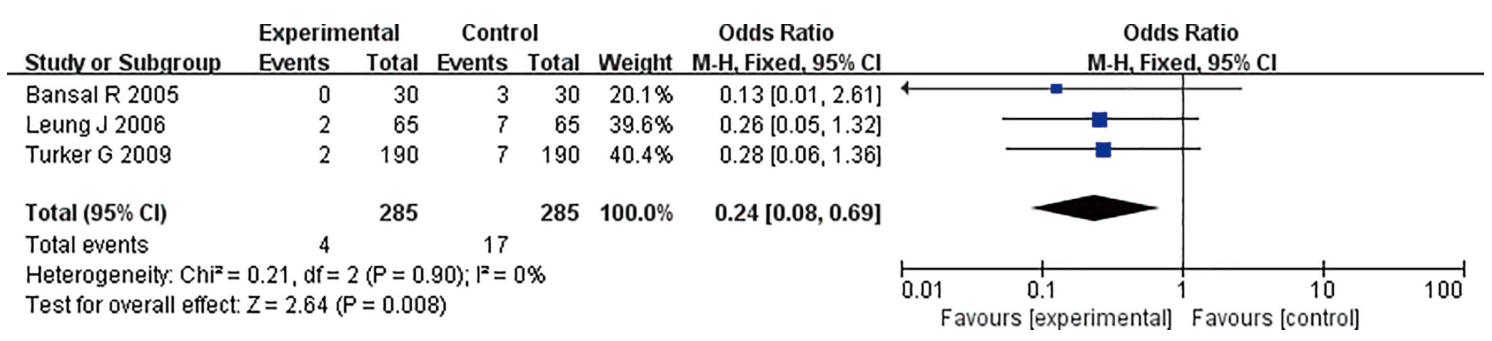

Figure 8 Forest plot comparing the hematoma formation rate of peripheral venipuncture catheterization guided by ultrasound to that of traditional methods.

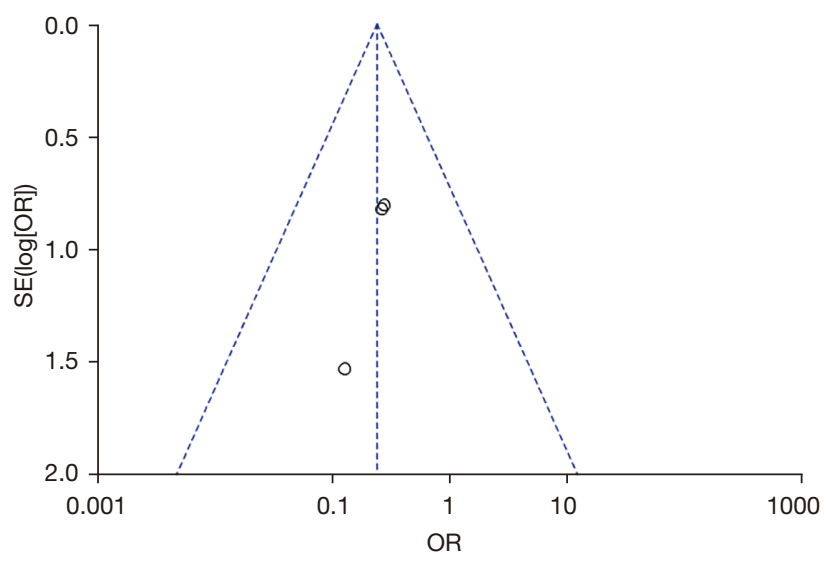

Figure 9 Funnel plot comparing the hematoma formation rate of peripheral venipuncture catheterization guided by ultrasound to that of traditional methods.

\section{Meta-analysis of the incidence of hemothorax with peripheral venipuncture and catbeterization guided by ultrasound}

Of the 8 studies included in this meta-analysis, 2 reported the incidence of hemothorax during peripheral vascular puncture and catheterization. For this analysis, 510 patients were rolled in the Exp group and 519 cases were in the Con group. Heterogeneity was found to be great $\left(\mathrm{I}^{2}=26 \%\right.$; $\mathrm{P}=0.25$ ), so a FEM was adopted. The meta-analysis results yielded on OR of 0.30 (95\% CI: $0.17-0.54 ; Z=4.00$; $\mathrm{P}<0.0001)$. Therefore, significant difference was found in the incidence of hemothorax between the two groups under different puncture methods $(\mathrm{P}<0.05$; Figure 12).

The funnel plot was basically symmetric, and most of the data corresponded to points within the $95 \%$ CI. It shows that there was no obvious publication bias in the included literature (Figure 13).

\section{Discussion}

Traditional clinical methods for peripheral venipuncture catheterization rely on anatomical markings on the body surface, successfully locating the pulse, and subjective, manual judgment of vascular elasticity by touch. These methods are somewhat limited: they are unable to identify vascular lesions or determine the location of needle and thread injury to adjacent structures (28). In addition, if a patient is in shock or is obese and the pulse is difficult to find, then the success rate of traditional methods is greatly reduced (29). Periphlebitis can also cause difficulties with traditional puncture methods if the patient has peripheral burns, scarring, obesity, or phlebitis (30). Deep venipuncture is difficult if the patient is obese, has a stubby neck, has anatomical variation, or has limited neck movement. Critically ill patients requiring deep vein catheters more often exhibit anasarca, difficulty breathing or lying down, shock, etc. These factors can all cause difficulties in successful deep vein puncture, including difficulties in determining the puncture point, depth, and angle. This can lead to repeated blind puncture, prolonged catheterization, catheterization failure, and even death in patients $(31,32)$. In recent years, the application of ultrasound-guided vascular puncture and catheterization has been expanded in clinical practice (33). Two-dimensional ultrasound guidance can clearly identify the relationship between arteries, veins, and surrounding structures, and accurately show the local anatomy (34). This can reduce unnecessary blood vessel and tissue damage, thus reducing complications such as accidental entry into arteries, damaged blood vessels, pneumothorax, and hemothorax (35).

Different from the ultrasound-guided arterial puncture, the superficial vein has a thin vessel wall and low blood pressure. Compared with the peripheral artery, the position is not fixed and superficial. In the process of searching for 


\begin{tabular}{|c|c|c|c|c|c|c|c|c|c|c|}
\hline Studv or Subgroup & $\begin{array}{l}\text { Experim } \\
\text { Events }\end{array}$ & Total & $\begin{array}{l}\text { Contr } \\
\text { Events }\end{array}$ & Total & Weight & $\begin{array}{l}\text { Odds Ratio } \\
\text { M-H, Fixed, } 95 \% \mathrm{Cl}\end{array}$ & \multicolumn{4}{|c|}{$\begin{array}{c}\text { Odds Ratio } \\
\text { M-H, Fixed, } 95 \% \mathrm{Cl}\end{array}$} \\
\hline Agawwal A 2009 & 0 & 40 & 1 & 40 & $10.2 \%$ & $0.33[0.01,8.22]$ & & & & \\
\hline Karakitsos D 2006 & 0 & 450 & 11 & 450 & $79.5 \%$ & $0.04[0.00,0.72]$ & & & & \\
\hline Leung J 2006 & 0 & 65 & 1 & 65 & $10.3 \%$ & $0.33[0.01,8.21]$ & & & & \\
\hline Total $(95 \% \mathrm{Cl})$ & & 555 & & 555 & $100.0 \%$ & $0.10[0.02,0.55]$ & & & & \\
\hline Total events & 0 & & 13 & & & & & & & \\
\hline \multicolumn{7}{|c|}{$\begin{array}{l}\text { Heterogeneity: } \mathrm{Chi}^{2}=1.38, \mathrm{df}=2(\mathrm{P}=0.50) ; \mathrm{I}^{2}=0 \% \\
\text { Test for overall effect: } Z=2.66(\mathrm{P}=0.008)\end{array}$} & 0.001 & $\begin{array}{l}0.1 \\
\text { oerimental] }\end{array}$ & $\begin{array}{l}10 \\
\text { Favours [c }\end{array}$ & $1000^{\circ}$ \\
\hline
\end{tabular}

Figure 10 Forest plot comparing the incidence of pneumothorax with peripheral venipuncture and catheterization guided by ultrasound to that of traditional methods.

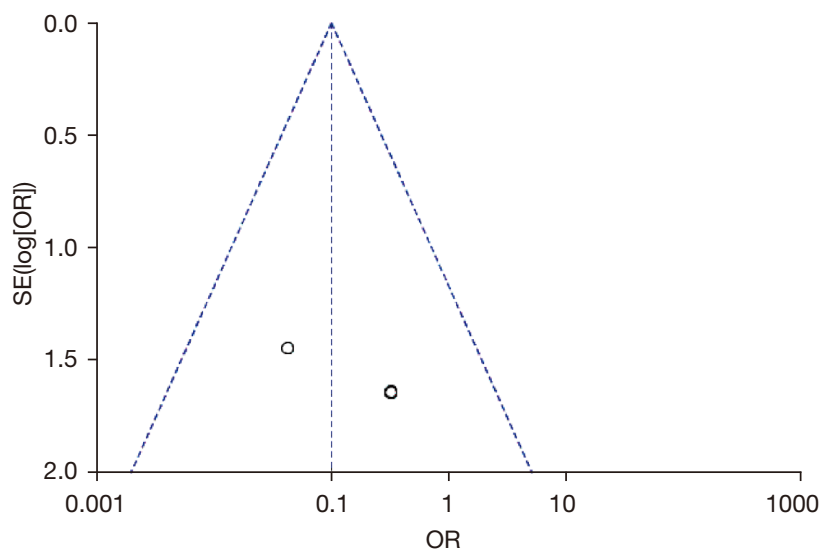

Figure 11 Funnel plot comparing the incidence of pneumothorax with peripheral venipuncture and catheterization guided by ultrasound to that of traditional methods.

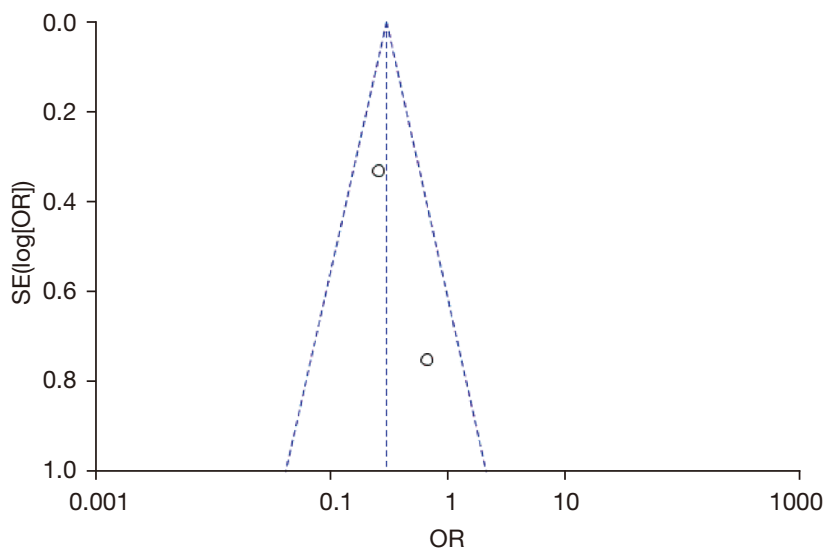

Figure 13 Funnel plot comparing the incidence of hemothorax with peripheral venipuncture and catheterization guided by ultrasound to that of traditional methods.

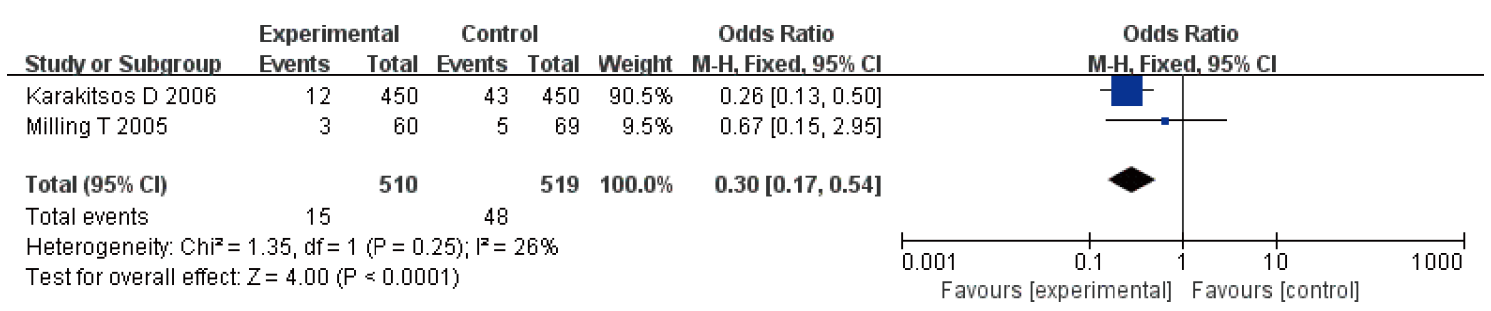

Figure 12 Forest plot comparing the incidence of hemothorax with peripheral venipuncture and catheterization guided by ultrasound to that of traditional methods.

superficial veins and during venipuncture, the ultrasound probe should be placed gently on the skin surface to avoid applying pressure under the premise of ensuring close contact with the skin and good imaging. To prevent the superficial vein from deforming or closing due to the contact pressure of the ultrasound probe, which will affect the puncture effect.

\section{Conclusions}

Meta-analysis of 8 studies has shown that, as compared to conventional catheterization, ultrasound-guided peripheral venipuncture catheterization exhibits fewer complications; lower puncture failure rates; and reduced incidence of arterial injury, hematoma formation, pneumothorax, and hemothorax. Since the follow-up time of the included 
studies was not consistent and most of the studies had a short follow-up time, it was not possible to draw any conclusions as to the comparative long-term quality of life for patients. Furthermore, the information collected in this study may have publication bias, which would affect the reliability of this meta-analysis.

Nevertheless, ultrasound-guided peripheral venipuncture catheterization exhibits clear advantages over traditional methods. It is a noninvasive, highly efficient technique, with a high one-time puncture success rate, fewer complications, and strong operability. Its use can improve the comfort of patients and avoid additional injuries. It should therefore be employed widely in clinical practice as an effective means of providing comfortable medical treatment.

\section{Acknowledgments}

Funding: None.

\section{Footnote}

Reporting Checklist: The authors have completed the PRISMA reporting checklist. Available at https://dx.doi. org/10.21037/apm-21-3163

Conflicts of Interest: All authors have completed the ICMJE uniform disclosure form (available at https://dx.doi. org/10.21037/apm-21-3163). The authors have no conflicts of interest to declare.

Ethical Statement: The authors are accountable for all aspects of the work in ensuring that questions related to the accuracy or integrity of any part of the work are appropriately investigated and resolved.

Open Access Statement: This is an Open Access article distributed in accordance with the Creative Commons Attribution-NonCommercial-NoDerivs 4.0 International License (CC BY-NC-ND 4.0), which permits the noncommercial replication and distribution of the article with the strict proviso that no changes or edits are made and the original work is properly cited (including links to both the formal publication through the relevant DOI and the license). See: https://creativecommons.org/licenses/by-nc$\mathrm{nd} / 4.0 \%$.

\section{References}

1. Prabhu MV, Juneja D, Gopal PB, et al. Ultrasoundguided femoral dialysis access placement: a single-center randomized trial. Clin J Am Soc Nephrol 2010;5:235-9.

2. Yonei A, Nonoue T, Sari A. Real-time ultrasonic guidance for percutaneous puncture of the internal jugular vein. Anesthesiology 1986;64:830-1.

3. Palepu GB, Deven J, Subrahmanyam M, et al. Impact of ultrasonography on central venous catheter insertion in intensive care. Indian J Radiol Imaging 2009;19:191-8.

4. Dowling M, Jlala HA, Hardman JG, et al. Real-time threedimensional ultrasound-guided central venous catheter placement. Anesth Analg 2011;112:378-81.

5. Hind D, Calvert N, McWilliams R, et al. Ultrasonic locating devices for central venous cannulation: metaanalysis. BMJ 2003;327:361.

6. Maecken T, Marcon C, Bomas S, et al. Relationship of the internal jugular vein to the common carotid artery: implications for ultrasound-guided vascular access. Eur J Anaesthesiol 2011;28:351-5.

7. Liu YT, Alsaawi A, Bjornsson HM. Ultrasoundguided peripheral venous access: a systematic review of randomized-controlled trials. Eur J Emerg Med 2014;21:18-23.

8. Bair AE, Rose JS, Vance CW, et al. Ultrasound-assisted peripheral venous access in young children: a randomized controlled trial and pilot feasibility study. West J Emerg Med 2008;9:219-24.

9. Stein J, George B, River G, et al. Ultrasonographically guided peripheral intravenous cannulation in emergency department patients with difficult intravenous access: a randomized trial. Ann Emerg Med 2009;54:33-40.

10. Stolz LA, Stolz U, Howe C, et al. Ultrasound-guided peripheral venous access: a meta-analysis and systematic review. J Vasc Access 2015;16:321-6.

11. Aponte H, Acosta S, Rigamonti D, et al. The use of ultrasound for placement of intravenous catheters. AANA J 2007;75:212-6.

12. Bahl A, Pandurangadu AV, Tucker J, et al. A randomized controlled trial assessing the use of ultrasound for nurseperformed IV placement in difficult access ED patients. Am J Emerg Med 2016;34:1950-4.

13. Bauman M, Braude D, Crandall C. Ultrasound-guidance vs. standard technique in difficult vascular access patients by ED technicians. Am J Emerg Med 2009;27:135-40. 
14. Bridey C, Thilly N, Lefevre T, et al. Ultrasound-guided versus landmark approach for peripheral intravenous access by critical care nurses: a randomised controlled study. BMJ Open 2018;8:e20220.

15. İsmailoğlu EG, Zaybak A, Akarca FK, et al. The effect of the use of ultrasound in the success of peripheral venous catheterisation. Int Emerg Nurs 2015;23:89-93.

16. Kerforne T, Petitpas F, Frasca D, et al. Ultrasoundguided peripheral venous access in severely ill patients with suspected difficult vascular puncture. Chest 2012;141:279-80.

17. Moher D, Jadad AR, Tugwell P. Assessing the quality of randomized controlled trials. Current issues and future directions. Int J Technol Assess Health Care 1996;12:195-208.

18. Chen JJ, Fu SY, Chiang CS, et al. Characterization of tumor vasculature distributions in central and peripheral regions based on Doppler ultrasound. Med Phys 2012;39:7490-8.

19. Egan G, Healy D, O'Neill H, et al. Ultrasound guidance for difficult peripheral venous access: systematic review and meta-analysis. Emerg Med J 2013;30:521-6.

20. Turker G, Kaya FN, Gurbet A, et al. Internal jugular vein cannulation: an ultrasound-guided technique versus a landmark-guided technique. Clinics (Sao Paulo) 2009;64:989-92.

21. Agarwal A, Singh DK, Singh AP. Ultrasonography: a novel approach to central venous cannulation. Indian J Crit Care Med 2009;13:213-6.

22. Airapetian N, Maizel J, Langelle F, et al. Ultrasoundguided central venous cannulation is superior to quick-look ultrasound and landmark methods among inexperienced operators: a prospective randomized study. Intensive Care Med 2013;39:1938-44.

23. Bansal R, Agarwal SK, Tiwari SC, et al. A prospective randomized study to compare ultrasound-guided with nonultrasound-guided double lumen internal jugular catheter insertion as a temporary hemodialysis access. Ren Fail 2005;27:561-4.

24. Grebenik CR, Boyce A, Sinclair ME, et al. NICE guidelines for central venous catheterization in children. Is the evidence base sufficient? Br J Anaesth 2004;92:827-30.
25. Karakitsos D, Labropoulos N, De Groot E, et al. Realtime ultrasound-guided catheterisation of the internal jugular vein: a prospective comparison with the landmark technique in critical care patients. Crit Care 2006;10:R162.

26. Leung J, Duffy M, Finckh A. Real-time ultrasonographically-guided internal jugular vein catheterization in the emergency department increases success rates and reduces complications: a randomized, prospective study. Ann Emerg Med 2006;48:540-7.

27. Milling TJ Jr, Rose J, Briggs WM, et al. Randomized, controlled clinical trial of point-of-care limited ultrasonography assistance of central venous cannulation: the Third Sonography Outcomes Assessment Program (SOAP-3) Trial. Crit Care Med 2005;33:1764-9.

28. Blomqvist A, Engblom D. Neural Mechanisms of Inflammation-Induced Fever. Neuroscientist 2018;24:381-99.

29. Duscha BD, Schulze PC, Robbins JL, et al. Implications of chronic heart failure on peripheral vasculature and skeletal muscle before and after exercise training. Heart Fail Rev 2008;13:21-37.

30. Douek PC. MultiHance in MRA of peripheral vasculature. Eur Radiol 2004;14 Suppl 7:O55-60; discussion O61-2.

31. Bertoglio S, Cafiero F, Meszaros P, et al. PICC-PORT totally implantable vascular access device in breast cancer patients undergoing chemotherapy. J Vasc Access 2020;21:460-6.

32. Hall TB, Matson M, Belli AM. Thrombolysis in the peripheral vascular system. Eur Radiol 2001;11:439-45.

33. Gavier B, Vazquez F, Gandara E. Antiphospholipid antibodies and lower extremity peripheral arterial disease - a systematic review and meta-analysis. Vasa 2016;45:325-30.

34. Matsunaga T, Kanzaki J, Hosoda Y. The vasculature of the peripheral portion of the human eighth cranial nerve. Hear Res 1996;101:119-31.

35. Hoey ET, Ganeshan A, Puni R, et al. Fresh blood imaging of the peripheral vasculature: an emerging unenhanced MR technique. AJR Am J Roentgenol 2010;195:1444-8.

(English Language Editors: E. Davies and J. Gray)
Cite this article as: Xiong X, Xiong Y, Liu G. Systematic review and meta-analysis: safety of ultrasound-guided peripheral venipuncture and catheterization. Ann Palliat Med 2021;10(11):11721-11732. doi: 10.21037/apm-21-3163 